\title{
Es difícil despertar a una persona que finge estar dormida
}

Katherine Miller

Directora de Asuntos Culturales Biblioteca "P. Florentino Idoate, S.J."

a palabra "dormido", en esta aseveración, talvez es una metáfora para un estado psicológico en que una persona está empañado con ilusiones y engaños. Además, "finjiendo" estar "dormido" implica una intencionalidad: finjir estar inconciente del mundo alrededor, pero adrede, con intención. Fingiendo estar dormido hasta el punto que no se lo puede despertar sin dificultad es un estado de conciencia que esconde la astucia que, a la misma vez, resiste esfuerzos de despertarlo a otra realidad.

Es una ironía elemental estar despierto y dormido a la misma vez. Muy listo quien puede mantener estas dos visiones simultáneamente. Se piensa en las visiones de sueño de los tiempos medievales: Piers Plowman finjiendo ser pastor de ovejas, acostado, dormido y simultáneamente despierto, al lado de una riachuelo mientras comenta, en su poema, sobre la justicia e injusticia de este mundo desde su sueño. Consideramos a Pablos en El Buscón de Francisco de Quevedo, disfrazado en vestuario de la nobleza, imaginando que no lo van a reconocer. O Pip en Grandes Esperanzas de Charles Dickens, víctima de su ilusión adoptada intencionalmente que está siendo preparado para casarse con Estela.

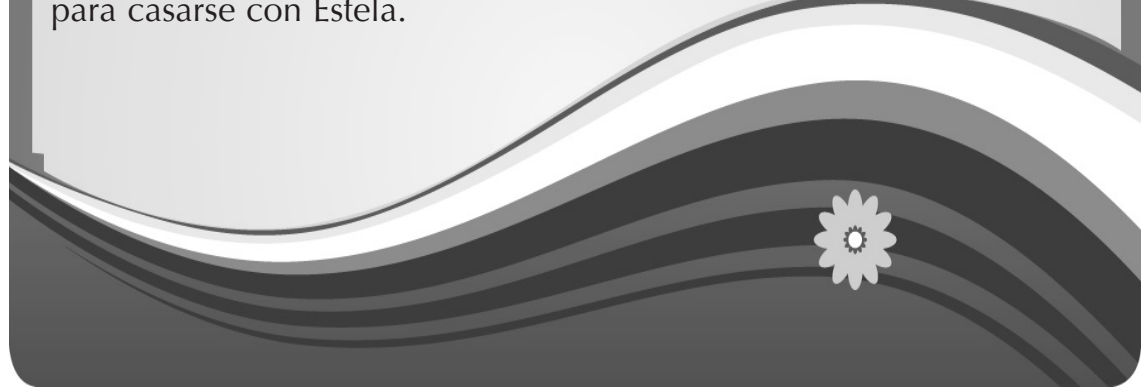


¿Quién quiere despertarlos, y por qué? ¿Y cuál es la realidad a que van a despertar? Los muy listos desean quedarse finjiendo un sueño que los proteja de las murallas invisibles contra que tendrán que enfrentarse si permitan que alguien los despierta. Mejor fingir, mejor listo y astuto, pero en su propio mundo, ensimismado.

Los individuos proyectados en la pantalla de una población arropada en el jardín pasado de la niñez de sus antepasados, que resisten despertarse, pasarán dolores psicológicos cuando una nueva realidad hace impacto. Sin embargo, aun con los ojos cerrados, se comienzan sentir las vibraciones terrenales de la máquina en el jardín, la dialéctica de las máquinas de la industrialización y su intrusión chocante en la conciencia pastoral, en el jardín de la agricultura con su ilusión de auto-suficiencia.

Es la novela, como género literario, que nos otorga permiso a despertar lentamente del sueño pastoral y confrontar la imposición del crecimiento hacia la construcción de un país que entra el mundo de una economía comercial y el comercio marítimo internacional. Así la época cuando la Reina Victoria ascendió el trono en 1837.

Pero, tomando algunos pasos atrás, durante el siglo XVIII, Daniel Defoe nos presenta la muy astuta, $y$ muy famosa, Moll Flanders, quien, "dormida" a la realidad de Londres comercial y turbulento, con toda su brutalidad, no deja su sueño, que es completamente imposible por su falta de credenciales y recursos económicos: el sueño de ser un "gentlewoman", alguien independiente económica y socialmente. Daniel Defoe, en su novela con título Moll Flanders, como Quevedo en la figura de Pablos en su novela, El Buscón, intentan despertar sus creaciones imaginarias quienes insisten ponerse el vestuario de sus sueños. Pero ni Moll ni Pablos se dejan despertar y siguen re-haciéndose con sus ilusiones intactos después de cada fracaso.

En el siguiente siglo después de Defoe y Quevedo, la máquina en el jardín se hace presente cada vez más, con toda su brutalidad, y con brillantes visiones del progreso. En un principio, la población de Inglaterra pastoral enfrenta la Revolución Industrial con los ojos cerrados. No desean abrirlos para ver y experimentar la transición cultural que los cubre hasta el cuello. El dolor de la realidad industrial es una trauma llena de cambios. Es una transición cultural difícil de enfrentar. Quedan resistiendo el despertar. Difícil despertar una persona que finje estar dormido.

Pero, entonces, aparece, en el siglo XIX, la novela, este objeto viviente, palpitando, que creció de los pasquines, y se propone romper las barreras entre la vida cotidiana 
y la vida interior-inesperada o espantosa--de los protagonistas. Los protagonistas de estas novelas a veces dejan a un lado sus quehaceres y miren al lector para comentar, para dar una explicación de las verdades de sus vidas interiores, sus verdaderas intenciones, que son invisibles a primera vista. Pero hay que explicarse a alguien: ergo, la novela. Se tiene que despertar, por lo menos, al lector, mostrando las posibilidades dobles y la ironía del contacto entre las vidas exteriores e interiores del protagonista, que no se ven cuando encuentra la persona en la calle. La novela nos despierta del sueño finjido y nos demuestra las realidades multifacéticas por bien o mal que sean.

Casi todas las novelas victorianas del siglo XIX se tratan, inevitablemente, de "la condición de Inglaterra" durante el orgullo y la agonía de la Revolución Industrial en Inglaterra durante los siglos XVIII y XIX. Inevitablemente, presentan esta realidad en unas visiones muy distintas de esta otra gran novela victoriana, los tres tomos de Capital, escrito en el Museo Británico y publicado en 1867.

En los tres tomos, Marx presenta su análisis de muchos temas: entre ellos, como funcionan la teoría del valor agregado y la crudeza de la industrialización. En Capital, Marx, como sus contemporáneos, Charles Dickens, Benjamin Disraeli, Elizabeth Gaskell y muchos otros escritores de novelas, utilizan la Inglaterra de la Revolución Industrial como su "case study" para la examinación literaria y política. Estos escritores de novelas trataron de los efectos de la Revolución Industrial en la economía y en las vidas de las clases que trabajaron en las nuevas fábricas. Como resultado de estos escritos publicados en forma de novelas serializadas, sale a la luz el funcionamiento defectuoso y dañino de partes de la sociedad inglesa durante el período cuando la Reina Victoria estaba en el trono.

Marx, el muy gentleman victoriano, describe esta Inglaterra, envuelta en los fuertes dolores de la industrialización, en un estilo elegante, fino $y$-hay que decirlo-muy "victoriano". (Leamos, por ejemplo, en Capital, sus alusiones a Shakespeare: Marx presta a Shylock de El Mercader de Venecia como vocero, utiliza las palabras mismas de Shylock tomadas del escenario isabelino, para ilustrar un punto en las páginas del primer tomo de Capital. Aparece, también, en las páginas de esta novela de Marx, la figura del Cíclope, de la Odisea de Homero, como alusión a los hombres e instrumentos del capitalismo brutal y rapaz en las fábricas de Manchester. No se tiene que multiplicar ejemplos).

En eso Marx, igual como los demás escritores de novelas victorianas, demuestra un respeto para la literatura clásica. Es el hambre 
intelectual y emocional de conocer y manejar las metáforas y asumir el humanismo representado que despiertan el lector, quiérase o no, a la examinación de la realidad interna y externa que se vive. Este hambre aparece en las novelas victorianas como un anhelo para la vida plena que otorga una educación en los clásicos. Dos ejemplos nos pueden servir aquí: El monstruo en la novela Frankenstein de Mary Shelley, y Thornton en Norte y Sur de Elizabeth Gaskell.

Tomamos, por ejemplo, Norte y Sur (publicado serializado en 1855), donde un clérigo de la Iglesia Anglicana, John Hale, pierde su fe, $y$, por conciencia, renuncia su "living" y traslada su familia al norte de Inglaterra a Milton, una representación ficticia de la ciudad de Manchester y sus fábricas de textileras mecanizadas que produce algodón. Además de la vida miserable de los trabajadores, Gaskell nos presenta Mr. John Thornton, empresario y dueño de una de las fábricas textileras mas grandes de la ciudad, Marlborough Mills.

Thornton, uno de los protagonistas de la novela, es consciente de que es mal educado y que tiene una personalidad brusca y dura por su vida de un capitalista, levantando su fábrica. Pide al clérigo, John Hale, clases individuales en los clásicos, para suavizar su temperamento e introducirlo al mundo de humanismo con la lectura de
Platón. Thornton va a la casa de Hale después de su trabajo de día en su fábrica para conocer el mundo que lo va a despertar a otras posibilidades que no existen en su vida comercial.

Ahora, el objetivo de Gaskell es de presentar la posibilidad de acercar los dueños-empresarios a los trabajadores para crear una situación de trabajo en la fábrica donde las necesidades médicas, educacionales y alimenticias pueden contribuir a suavizar la dureza de su trabajo. Presenta muchas maneras de alcanzar este acercamiento. Los deseos de Thornton, el "Manchester Man" inmerso en "la Condición de Inglaterra", son centrales. Pero más, presenta el anhelo de Thornton para enriquecer e humanizar su vida interior, sus conversaciones, su habilidad de argumentar, su comportamiento social, sus modales. Thornton mismo efectúa las modificaciones en su carácter y personalidad que son, finalmente, productos de su lectura y conversación con el clérigo. Como resultado de sus encuentros y tutoriales, Thornton va con confianza a conocer sus homólogos, los empresarios continentales, en la Gran Exhibición Internacional de la Industrialización de 1851 en el Crystal Palace de Londres.

Es que la novela, como género, desde el siglo XVIII con Robinson Crusoe y Moll Flanders, capturó su lectores con la presentación 
no solamente de la vida cruda de los comerciantes y mercaderes de Londres, si no también con miradas hacia la vida interior de estas personas. Daniel Defoe (Moll Flanders, Roxana, Robinson Crusoe), Lawrence Sterne (La Vida y opiniones de Tristram Shandy, Gentleman) y Henry Fielding (Tom Jones, Expósito) y otros quienes escribieron las primeras, y deliciosas, novelas, jugaron con enseñar, exponer, exhibir la vida interior en su contacto irónico con la vida pública del individuo.

Cuando Thornton, en North and South, actúa para contratar al clérigo para estudiar Platón y otros textos, está exhibiendo sus deseos interiores de reclamar su humanidad en medio del infierno de los tiempos cambiantes que producen riqueza y pobreza, rabia, sindicalismo militante, las huelgas (un fenómeno nuevo) y antagonismos de clase de la sociedad en que le toca crear fábricas industrializadas $y$ trabajadores que producen $y$ que sufren. Es que su humanidad lo obliga estudiar para alimentar su vida interior en medio del caós de la Revolución Industrial. Los resultados se ven, al final, cuando Thornton efectúa la re-estructuración de su fábrica para atender las necesidades humanas de los trabajadores.

Este tema de la importancia de la vida interior, la humanización y el sentimiento de justicia que surge paulatinamente en el proceso de la "educación" como fuerza para el progreso y el optimismo, aparece continuamente en las novelas de George Eliot (Felix Holt, Radical), Benjamin Disraeli (Sybil, o, Las Dos Naciones), Charles Dickens (David Copperfield y Dombey and Son), Elizabeth Gaskell (Mary Barton: a Tale of Manchester Life) y muchos otras novelas victorianas.

La novela victoriana como género literario presenta, desde varias ópticas, propuestas para una sociedad utópica que teja una relación entre los dueños-empresarios de fábricas y los trabajadores y que reconoce que la humanización de la vida interior es parte de este proceso. Estas novelas son, de hecho, amortiguadores para los dolorosos golpes físicos y psicológicos que producen los procesos crueles y turbulentos que aguantaron los ingleses durante todo un siglo desde la ampliación del comercio internacional hasta la transformaciónde la vida doméstica de la familia y los individuales. Eso todo a causa de la Revolución Industrial.

Así es que, mientras Marx y Engels, Saint-Simón y Fourier en Francia y Robert Owens en Inglaterra trabajaban con conceptos y abstracciones, ejemplos y procesos. Mientras tanto, la novela, de otro modo, floreció con metáforas e imágenes, que tocaron la conciencia de sus lectores con presentar la posibilidad de humanizar los 
procesos de la industrialización, del comercio en general, de los trabajadores de las fábricas y minas y de los empresarios.

El sub-texto de estas novelas era la externalización, en prosa, de la vida interior por medio de la humanización de la vida exterior que había llegado a caer en el estupor del lodo, humo negro y miseria de la industrialización y comercio. La propuesta de estas novelas era la educación, y, por medio de esta, el acercamiento de la vida exterior a la vida interior para minimizar la separación y cerrar la brecha.

Thornton es un emblema del industrialista que reconoce la necesidad de la educación en los clásicos en Norte y Sur. Y, por supuesto, se había vislumbrado estas ideas desde finales del siglo XVIII en La Vindicación de los Derechos de la Mujer de Mary Wollstonecraft. En la novela Frankenstein, o, el Promoteo Moderno de su hija, Mary Shelley, el monstruo creado por Victor Frankenstein aprende a leer, sentir y entender la situación humana con leer el poema El Paradiso Perdido de John Milton y también Las Vidas Paralelos de Plutarco [o, "las historias de los primeros fundadores de las antiguas repúblicas" como dice Mary Shelley].

Es que los pueblos de todas clases de la Inglaterra victoriana recibieron la industrialización forsozamente como un imperativo, po- sitivo por el progreso y la riquezas que confirió, y, simultáneamente, tuvieron que vivir la deprimiente condición de la pobreza y opresión que la Revolución Industrial trajo consigo. Este choque cultural implicó, a la vez, el deterioro y derrumbe cultural de las ciudades de su sociedad con las negras fábricas, las aguas negras, el aire negro, el hambre y depresión de Manchester, Leeds y Birmingham y otras ciudades del norte.

Durante los siglos XVIII y XIX los ingleses habían amado a sus jardines, su agricultura y la vida rural donde el sol medía el tiempo y no había ni suciedad ni hambre como en las ciudades. No querían despertarse de su sueño pastoral. Pero poco a poco, les cayeron encima el miedo del cambio y la esperanza de la felicidad por medio de la riqueza que resultó de los cambios culturales tan angustiosos, producidos por la industrialización. Fue difícil despertarlos. Las novelas presentaron, en sus páginas, como despertar y aguantar las traumas de la transición (desde un mundo pasado en el campo, folclórico en que deseaban quedarse, hasta un mundo del enfrentamiento con la mecanización y los ferrocarriles). Después, los ferrocarriles literalmente violaron las ciudades.

En este pequeño país, aquí, ahora, una revolución industrial es apenas comenzando. Podemos mirar para atrás a la Inglaterra de 
la Reina Victoria, para ver algo del futuro de lo que producirá la Revolución Industrial que avecina. En eso, las novelas puedan servir como amortiguadores de cambio. Novelas describen y proponen en metáforas, imágenes, fotografías habladas de los cambios industriales. Las novelas ayudaron y ayudarán a absorber el choque cultural que este avance en la economía de un país implica.

Pero, hoy, en este país, la novela, así como existe en su estado actual en el siglo XXI, parece siempre mirar hacia atrás. Mirar hacia el pasado es de re-vivir continuamente el momento en que algunos sectores de la población llevaban la delantera y se establecieron una suerte de control, proyectando su visión del destino para el país. Escriben el mismo cuadro en repetidas veces en lugar de construir el futuro no proyecta mas que lo mismo. Una vuelta hacia el futuro pueda servir a los lectores, toda la población, sobrevivir el crecimiento económico que va a estirar hasta lo máximo las conciencias que desean quedar finjiendo estar dormido. ¿Quién desea sobrevivir el dolor de una transición hacia una Revolución Industrial sin empaques y amortiguadores?

El pasado no siempre es la mejor lámpara eterna para iluminar el futuro, especialmente si es de celebrar el pasado pastoral junto con el espíritu guerrero como las únicas maneras de poder ejercer control sobre la vida. Finjiendo dormir este sueño, constantemente, constituye una resistencia al despertar.

¿Sería tiempo de pedir un cambio de velocidad-desde los caballos de la guerra hacia el ferrocarril, los puertos y carreteras? La futura industrialización de El Salvador se llevará acabo no solamente en las fábricas, ferrocarriles y minas, si no, también en los círculos concéntricos de culturas nacionales e internacionales. Cambios económicos implican cambios en la vida cultural. Puesto de otra manera, una revolución industrial y económica es también, necesariamente, una transición cultural.

¿Hay un concepto de progreso y optimismo en la sociedad victoriana que ayudaban absorber estos cambios. ¿Hay conceptos de progreso y optimismo para animar a El Salvador durante sus transiciones? No es una ilusión ni una república de aire que se está construyendo en la economía nacional. La novela constituye una herramienta ahora-igual como en el siglo XIX--que podría facilitar la sobrevivencia psicológica de un pueblo lector y ayudar, a la misma vez, enfrentar los procesos turbulentos de la Revolución Industrial en este país en el siglo XXI, así como hizo en la Inglaterra victoriana del siglo XIX.

Esta herramienta, la novela, es eficáz en dibujar las transiciones culturales que representarán un 
cambio de valores culturales. Una revolución industrial pueda implicar unos cambios hasta en la modalidad de vida y en el entendimiento que preparan, ambos. El camino puede ser hacia la conformación de identidades culturales múltiples, no la destrucción de la identidad nacional.

Imposible decir que clase de culturas estarán surgiendo ahora cuando apenas comienza la industrialización en este país. ¿Serán unas culturas múltiples compuestas de las culturas nacionales existentes, de las identidades rotas, de los valores nacionales reafirmados y todo lo que forma parte de las tendencias fuertes empujando al país-quiérase o no-a entrar la globalización del comercio e intercambio cultura? Algunos de estos elementos son muy bienvenidos-como apertura y flexibilidad hacia otras culturas, comunicación creciente, y los beneficios de los mercados transnacionales con los rasgos variopintos de cultura que vienen con un comercio inmerso en el ámbito internacional.

La novela nacional de un país, en el siglo XXI, igual como en el siglo XIX, se ubican en algún continuum entre la cultura del estado y la cultura de la expansión de una economía que produce ganancias (no se lee "avaricia"). Novelas pueden servir de herramientas simbólicas para un estado que no siempre tiene que mirar hacia la concepción de un estado ensimismado, sus miradas vueltas solamente hacia adentro. Este género-la novela-es un locutor, comentando como un coro, explicando lo que está pasando a su alrededor. De otro modo, sin una nueva concepción de la novela nacional, se queda usando "Orejeras" que simplemente son buenos herramientas para fingir estar dormido. $\mathrm{Y}$ el pasado, ortodoxo y heroico, puede servir de "orejera" para un estado igual como para un caballo.

Así que, un principio básico es que la velocidad de la industrialización depende en el grado de resistencia o espíritu de receptividad de una sociedad en el proceso de modificar su cultura tradicional. Los tratados internacionales, así como los movimientos físicos de bienes desde puertos en un lado del continente hacia el océano que se lleva a Asia o hacia Europa ya casi están funcionando. Visiones culturales esperan ser creados para inculcar en la vida interior de la gente como sobrevivir y avanzar en la revolución industrial de El Salvador. La premisa básica es que la industrialización viene a modificar y agregar nuevas visiones culturales a las culturas tradicionales.

En casi cada novela se percibe, junto con la crítica social, una representación de los valores éticos que son favorables para el crecimiento, innovación y cambio científico. Estas ideas son las mis- 
mas que fragmentaron la cultura tradicional de la sociedad victoriana igual como el psyche individual. Podemos pensar solamente en Middlemarch de George Eliot.

También hay comentarios para los días actuales, desde los espejos lejanos victorianos. Se puede leer sobre la crítica de un sistema legal que puede animar el crecimiento económico y los derechos a la propiedad privada que deben ser protegidos para que no sufren arbitrariedades. Eso es el tema de la novela Casa Desolada (Bleak House) de Charles Dickens, una obra maestra.

Ahora, regresando a América Central, la Nueva Novela salvadoreña, así como la novela victoriana, puede despertar la gente del sueño que están finjiendo; eso de no querer ver que la nueva vida económica cambiará la vida cultural del país con agregar nuevas visiones y prácticas y maneras de comportarse. Para aguantar los cambios y para contribuir, también a cumplir con estos cambios necesarios para el progreso del país--se necesita un amortiguador o colchón porque los cambios mismos traen dolor cuando la sociedad comienza a entender que hay una máquina en el jardín del paraíso pastoral.

¿Es el caso que el país despertará culturalmente cuando ya está encima la revolución industrial que se avecina? Talvez las nuevas identidades del futuro, en parte, serán compuestas de la grandeza de una nación marítima e internacional en su adaptación, modificación y ampliación cultural ante este nuevo escenario, sin perder la cultura nacional del pasado. Sería un salto si la Nueva Novela salvadoreña podría representar percepciones de la vida pública y de la vida interna de la gente quienes experimentan la industrialización de su país. No siempre se tiene que confeccionar la identidad con fragmentos del pasado pastoral o guerrero. Se puede agregar una visión de la vida futura: industrial, internacional y basado en el concepto de una nación marítima con el puerto internacional como fuente de riqueza y también, fuente de una identidad cultural internacional que viene del mar.

Mientras se decide si vale la pena la propuesta de la Nueva Novela salvadoreña con las características propuestas, ¿Sería posible que los que van a impulsar estos cambios de relaciones industriales, empresariales y culturales con otras naciones pueden meditar la posibilidad de aportar a la nación algo de si mismos? Su humanización incluirá el hecho de servir como ejemplos a los políticos de cómo dejar a un lado la arrogancia y el antagonismo de "quien grita mas fuerte gana el argumento".

Son los empresarios, en este escenario, entonces, quienes serán los líderes en las relaciones con el demás del mundo-relaciones de 
intercambio comercial y cultural. Serán los representantes de su país de un nivel de discurso cultural igual como exhiben los empresarios de otros continentes. Su argumentación, su conversación social, sus negociaciones pueden ser a la altura de cualquier representante de cualquier país porque estarán preparados con la confianza que provee una educación complementaria. Esta confianza puede animar a la fuerza de negociar inversiones.

Los empresarios de una nación representados en las novelas, son la fuente de poder y el potencial de la riqueza comercial. Ellos representan a la nación internacionalmente en sus relaciones comerciales y culturales. ¿Será que, por eso, están obligados a prepararse para el encuentro con llenar sus costales con una conversación social de altura, conocimientos de otras culturas, pasado y presente, elegancia en su discurso y argumentación?

$¿ \mathrm{O}$, es que el arte de la conversación está perdido? No. Se la puede recuperar. Esta es la preparación que se ofrece a los empresarios para que pueden ir al encuentro internacional con lo que un escritor del Renacimiento italiano denominó sprezzatura: la gracia que esconde la gracia en la conversación y negociación. Eso viene con una preparación por medio de una educación complementaria.

$1^{\circ}$ de septiembre de 2012 